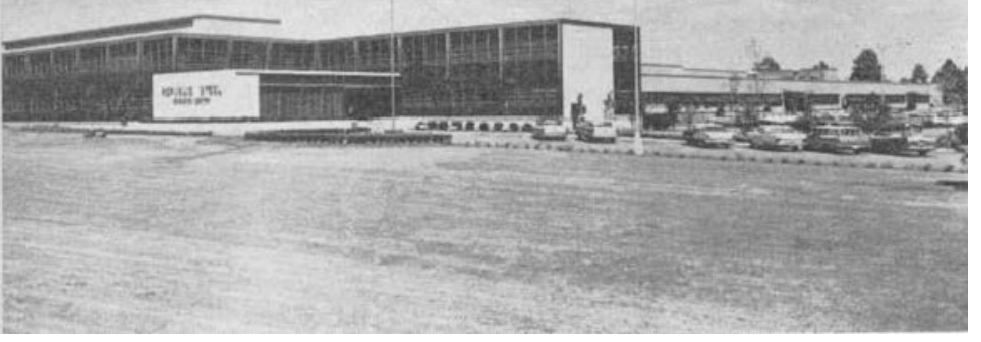

Below-A technician pours highly purified and reduced metallic iron powder into a funnel as the second step in Republic's new strip steel rolling process. The powder is compressed into a semi-solid strip by four rolls.

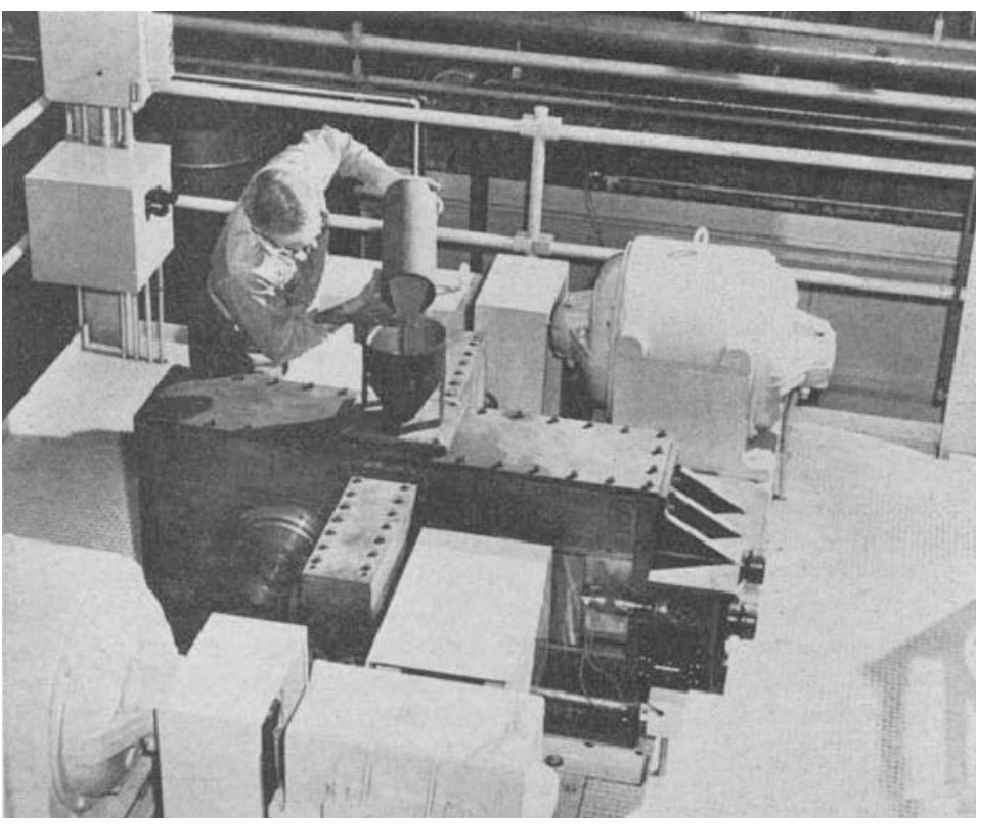

Below-A 1000-lb capacity electric furnace at Republic's new lab is being devoted to studies of refractories, both for service life and effect of various refractory compositions on properties of steels produced.

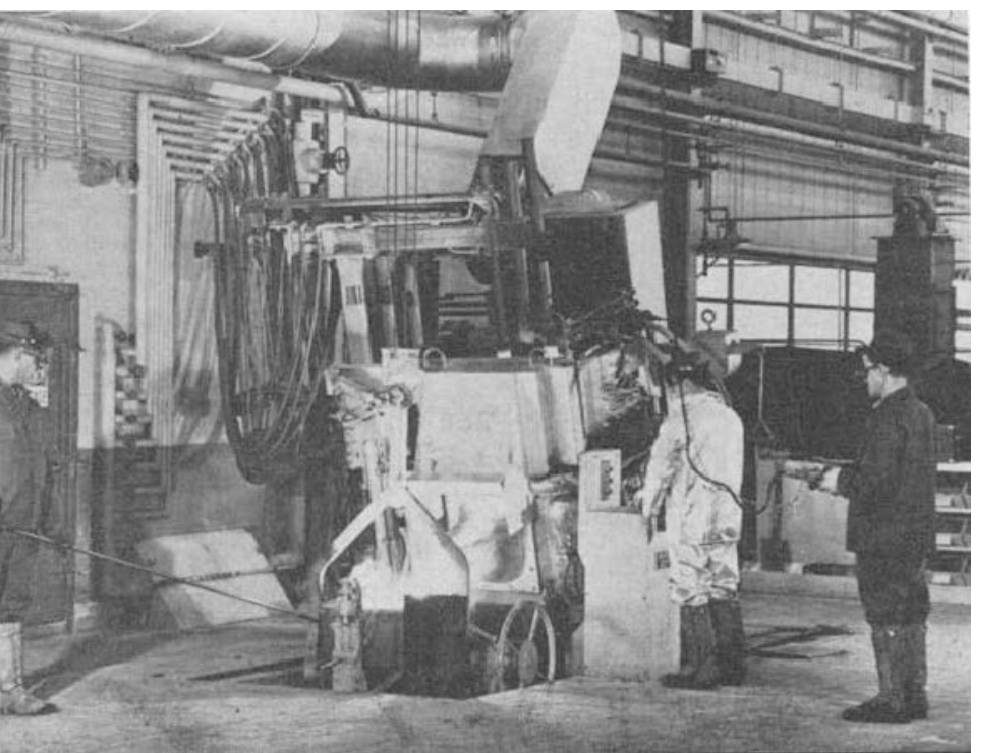

\section{Republic Shows}

\section{Direct Stripmaking Technique}

ewest scientific laboratory in the steel industry, Republic Steel Corp.'s \$5 million research center, was opened on June $18 \mathrm{th}$. The new facility is located on a 106-acre tract in Independence, Ohio, 10 $\mathrm{mi}$ south of downtown Cleveland. When the cornerstone of the center was laid in 1957, it was dedicated to Mr. Charles M. White, Chairman of the Board at Republic, in recognition of his long-standing interest in research, especially in new and better processes for producing steel.

Speaking at the dedication ceremonies, Mr. T. F. Patton, president of the Company, said that while Republic had developed its share of new steels and steel products in the past, "steel industry research, to date has only scratched the surface. From ore to finished product, steel technology is undergoing a revolution which is certain to gain momentum in the years ahead."

Describing the type of work to be carried on at the new center, Mr. Patton told those attending the ceremonies that " 30 pct of the budget will be applied to research projects designed to show results in one to three years . . . 30 pet to exploratory projects keyed to a five-year schedule, . . . another 30 pet allocated to long-range study projects . . . and 10 pct to pure science-fundamental research projects which have no immediate application ..."

Mr. Peter Robertson, vice president in charge of research and planning, took the laboratory dedication ceremonies as occasion to announce the successful development of a process for producing strip steel from iron ore, without melting. This process bypasses coke ovens, blast furnaces, open hearths and blooming mills. From the laboratory stage of development, Republic plans a continuous pilot plant line in which larger quantities of materials can be handled.

The process consists of three major steps: First, iron ore is highly purified and reduced to metallic iron powder. Second, it is funnelled between four rolls where it is compressed into a semi-solid strip. Finally, this green strip passes through a furnace where it is heated to $2200^{\circ} \mathrm{F}$ in a reducing atmosphere and passes on through a series of hot strip rolling stands. This reduces the strip to the desired gauge and full density, and produces hot-rolled steel in coils. Mr. Robertson said that these coils have the same quality as conventionally made steels: "We have made steel in the laboratory which offers the same strength, ductility, and ability to be fabricated into finished parts as steel produced by other methods."

It can be expected that this and other new products and processes will be said to have had their origin in this modern and complete research facility. 